\title{
Excess deaths reveal the true spatial, temporal, and demographic impact of COVID-19 on mortality in Ecuador
}

\author{
Authors: Leticia Cuéllar1, Irene Torres,", Ethan Romero-Severson ${ }^{3}$, Riya Mahesh ${ }^{3,4}$, \\ Nathaniel Ortega ${ }^{3,5}$, Sarah Pungitore ${ }^{3,6}$, Nicolas Hengartner ${ }^{3, *}$ and Ruian $\mathrm{Ke}^{3, *}$
}

\author{
Affiliations: \\ ${ }^{1}$ A-1 Information Systems and Modeling, Analytics, Intelligence and Technology Division, Los Alamos \\ National Laboratory, NM87545, USA. \\ ${ }^{2}$ Fundación Octaedro, Quito, Ecuador. \\ ${ }^{3}$ T-6 Theoretical Biology and Biophysics, Theoretical Division, Los Alamos National Laboratory, \\ NM87545, USA. \\ ${ }^{4}$ Department of Biology, University of Texas, Austin, Texas, 78712, USA. \\ ${ }^{5}$ University of California Santa Barbara, Santa Barbara, CA 93106, USA. \\ ${ }^{6}$ Program in Applied Mathematics, University of Arizona, Tucson, Arizona 85721, USA. \\ *Correspondence should be addressed to: \\ Leticia Cuéllar \\ Email: leticia@lanl.gov \\ Nicolas Hengartner \\ Email: nickh@lanl.gov \\ Irene Torres \\ Email: irene.torres@octaedro.edu.ec \\ Ruian Ke \\ Email: rke@lanl.gov
}

\begin{abstract}
Background: In early 2020, Ecuador reported one of the highest surges of per capita deaths across the globe.

Methods: We collected a comprehensive dataset containing individual death records between 2015 and 2020 from the Ecuadorian National Institute of Statistics and Census and the Ecuadorian Ministry of Government. We computed the number of excess deaths across time, geographical locations and demographic groups using Poisson regression methods.

Results: Between January $1^{\text {st }}$ and September $23^{\text {rd }}, 2020$, the number of excess deaths in Ecuador is 36,402 (95\% CI: $35,762-36,827$ ) or 208 per $10^{5}$ population, which is $171 \%$ of the expected deaths in that period in a typical year. Only $20 \%$ of the excess deaths are attributable to confirmed COVID-19 deaths. Strikingly, in provinces that were most affected by COVID-19, such as Guayas and Santa Elena, the all-cause deaths are more than double the expected number of deaths that would have occurred in a normal year. The extent of excess deaths in men is higher than in women, and the number of excess deaths increases with age. Indigenous populations had the highest level of excess deaths among all ethnic groups.

Conclusions: Overall, the exceptionally high level of excess deaths in Ecuador highlights the enormous burden and heterogeneous impact of COVID-19 on mortality especially in older age groups and indigenous populations in Ecuador that was not fully revealed by COVID-19 death counts. Together with the limited testing in Ecuador, our results suggest that the majority of the excess deaths were likely to be undocumented COVID-19 deaths.
\end{abstract}

NOTE: This preprint reports new research that has not been certified by peer review and should not be used to guide clinical practice. 1 
medRxiv preprint doi: https://doi.org/10.1101/2021.02.25.21252481; this version posted March 1, 2021. The copyright holder for this preprint

(which was not certified by peer review) is the author/funder, who has granted medRxiv a license to display the preprint in perpetuity.

It is made available under a CC-BY-NC-ND 4.0 International license .

\section{Introduction}

The coronavirus disease 2019 (COVID-19) pandemic has caused high morbidity and mortality across the globe. The total number of confirmed COVID-19 deaths is approximately 1.8 million by the end of $2020^{1}$. However, this number only partially reflects the total burden of COVID-19 on mortality, because it does not include undocumented COVID-19 deaths or other causes of deaths due to societal disruptions. A more accurate measure of the burden of COVID-19 on mortality is therefore the excess deaths ${ }^{2,3}$, i.e. the number of all-cause deaths exceeding the expected number of deaths in a typical year without COVID-19. This measure is especially relevant for countries where testing capacity is limited, such as Ecuador ${ }^{4}$, which may lead to substantial underreporting of COVID-19 cases and deaths.

Excess deaths in 2020 have been formally estimated previously for many high-income countries with high COVID-19 cases, including the United States (US) $)^{5-8}$, England and Wales ${ }^{9}$, Italy ${ }^{10,11}$, and middle income countries, such as Brazil ${ }^{12}$. The numbers of all-cause deaths range between $120 \%$ and $131 \%$ of expected deaths in these countries, i.e. between $20 \%$ and $31 \%$ of excess deaths, highlighting the heavy burden of COVID-19 spread directly on mortality, despite differences in demographics, social mixing patterns and health care systems. In these countries, a major fraction of excess deaths (between $67 \%$ to $80 \%$ ) are attributable to COVID-19 deaths $5,8,9,11$, suggesting that the majority of excess deaths are caused directly by COVID-19 infections. In contrast, Ecuador reported a relatively small number of COVID-19 deaths ${ }^{13}$; however, a surprisingly large number of excess deaths was reported in the Our World in Data online database ${ }^{13}$, in a newspaper during early COVID-19 outbreak in April $2020^{14}$ and more recently in a study ${ }^{15}$. This raises the questions about how the excess deaths vary temporally, spatially and demographically and how they are related to COVID-19 spread in Ecuador.

Here, by analysing a rich dataset containing death records from Ecuador during 2015-2020, we provide a comprehensive analysis of the spatial, temporal and demographic patterns of excess allcause deaths in Ecuador between January 1 and September 23 of 2020. We show that the extent of excess deaths in Ecuador is several folds higher than many countries severely affected by COVID19. In addition, we found the spatial, temporal and demographic pattern of excess deaths reveal a much more severe early burden of COVID-19 in Ecuador and a more complex spaciotemporal distribution of COVID-19 deaths than is apparent in the official death reports.

\section{Methods}

\section{Data}

Death records from 2015-2019 for all-cause mortality were obtained from the Ecuadorian National Institute of Statistics and Census. The records include age, sex, and ethnicity of the diseased, place of death registration, residence, and the International Classification of Disease (ICD) code for the cause of death. The Ecuadorian Ministry of Government provided death records from January 1st, 2020 to September 26th, 2020 containing sex, age, and registration and residence location by parish, canton, and province, but without the cause of death. There are 24 provinces in Ecuador. We ignore the three smaller "Not Delimited Areas" located along various provinces' borders. We use the 2020 population estimates from the INEC (the Ecuadorian National Institute of Statistics and Census).

Individual records of COVID-19 incidence and testing for Ecuador were obtained from the Ecuadorian Ministry of Public Health. All records were aggregated at the weekly level and binned 
medRxiv preprint doi: https://doi.org/10.1101/2021.02.25.21252481; this version posted March 1, 2021. The copyright holder for this preprint (which was not certified by peer review) is the author/funder, who has granted medRxiv a license to display the preprint in perpetuity. It is made available under a CC-BY-NC-ND 4.0 International license .

by sex, age group, and province. Ethics committee approval was obtained from the Ecuadorian Ministry of Public Health. The analysis by Los Alamos National Laboratory team was approved by that institution's IRB.

\section{Statistical Methodology}

To estimate the expected number of deaths in the absence of COVID-19, we fit a Poisson regression to the binned weekly death counts from 2015 to 2019. The regression predicts the number of weekly deaths as a function of the week of the year to account for annual variations, the province, and deceased demographics (sex and age group). Since the 2020 death records have ethnicity up to July 30 , we fitted a second model adding ethnicity as a covariate.

We calculate the number of weekly excess deaths in 2020, by subtracting from the 2020 deaths the number of expected or baseline deaths calculated with the Poisson regression model. We define the excess death factor (EDF) as the ratio of 2020 observed deaths over the expected deaths. See Supplementary Materials for details of the statistical model and the calculation of $95 \%$ confidence intervals for the number of deaths.

\section{Results}

\section{Excess deaths at the country level}

We first predicted the expected number of all-cause deaths between January 1 and September 23, 2020 using a Poisson regression model fitted to deaths data collected between 2015 and 2019 (Fig. S1 and see Methods and Supplementary Materials). We estimated that the expected number of allcause deaths up to September 23, 2020 is 51,360 (CI: 50,935-52,000). The number of reported total all-cause deaths during this period is 87,762 , leading to the number of excess deaths of 36,402 , i.e. $71 \%$ higher than expected (Table 1). This is in stark contrast to the percentages estimated for the US (20\% of excess deaths $)^{5,8}$, England and Wales $(31 \%)^{9}$, and Brazil $(22 \%)^{12}$. Normalized by the population size of Ecuador in 2020 (i.e. 17,468,736 according to the INEC (the Ecuadorian National Institute of Statistics and Census), the number of total all-cause deaths is 502 per $10^{5}$ population. The number of excess deaths is 208 per $10^{5}$ population, i.e. almost 3 fold higher than the estimate for the US (72 per $10^{5}$ population $)^{5}$.

Up to September 23, 2020, there were 7,410 officially reported COVID-19 deaths in Ecuador, which only account for $20 \%$ of the total all-cause excess deaths $(36,402)$. This is a much lower percentage than those reported in countries, such as the US $(67 \%)^{5,8}$, and England and Wales $(87 \%)^{9}$.

Time series of the total all-cause deaths suggest that the number of reported deaths started to become higher than expected in mid-March 2020, shortly after the first COVID-19 case was confirmed in Ecuador on February 29 (Fig. 1). There exist two waves of excess deaths, i.e. a first major wave between late March and April, and a second minor wave between July and early August (Fig. 1). The first wave started in the week of March 11-17. The number of excess deaths increased extremely rapidly and reached the highest level, i.e. 33 per $10^{5}$ population per week (or a total of 7,133 deaths per week; see Fig. S2) in the first week of April. Remarkably, this is over 5 times the number of expected deaths per week (Fig. S2). The number of weekly excess deaths declined afterwards to approximately 5 per $10^{5}$ population per week (Fig. S2). This rapid decline coincides with the period of strict lockdown implemented by the Ecuador government ${ }^{16}$. 
medRxiv preprint doi: https://doi.org/10.1101/2021.02.25.21252481; this version posted March 1, 2021. The copyright holder for this preprint (which was not certified by peer review) is the author/funder, who has granted medRxiv a license to display the preprint in perpetuity.

It is made available under a CC-BY-NC-ND 4.0 International license .

Table 1. Mortality and estimated excess deaths between January 1 and September 23, 2020.

\begin{tabular}{|c|c|c|c|c|c|c|c|}
\hline Jurisdiction & $\begin{array}{c}\text { Expected Deaths } \\
(95 \% \mathrm{Cl})\end{array}$ & $\begin{array}{c}\text { Observed } \\
\text { Deaths }\end{array}$ & $\begin{array}{c}\text { Excess Death } \\
(95 \% \mathrm{Cl})\end{array}$ & $E D F^{*}$ & $\begin{array}{c}\text { Mortality } \\
\text { per } \\
100,000\end{array}$ & $\begin{array}{c}\text { COVID } \\
-19 \\
\text { Deaths }\end{array}$ & $\begin{array}{c}\text { ED } \\
\text { Attributed } \\
\text { to COVID- } \\
19 \text { Deaths } \\
\%\end{array}$ \\
\hline Ecuador & $\begin{array}{r}51360 \\
(50935-52000)\end{array}$ & 87762 & $\begin{array}{r}36402 \\
(35762-36827)\end{array}$ & 1.71 & 502 & 7410 & 20 \\
\hline AZUAY & $2844(2735-2973)$ & 3582 & 738 (609-847) & 1.26 & 406 & 177 & 24 \\
\hline BOLIVAR & $596(536-657)$ & 816 & $220(159-280)$ & 1.37 & 389 & 47 & 21 \\
\hline CAÑAR & $778(720-852)$ & 1061 & $283(209-341)$ & 1.37 & 377 & 61 & 22 \\
\hline CARCHI & $497(432-576)$ & 674 & $177(98-242)$ & 1.36 & 361 & 79 & 45 \\
\hline CHIMBORAZO & $1710(1614-1832)$ & 2556 & $846(724-942)$ & 1.50 & 488 & 288 & 34 \\
\hline СОТОРАХI & $1251(1161-1354)$ & 1840 & $589(486-679)$ & 1.47 & 376 & 213 & 36 \\
\hline EL ORO & $2088(2027-2238)$ & 3800 & $\begin{array}{r}1712(1562- \\
1773)\end{array}$ & 1.82 & 531 & 399 & 23 \\
\hline ESMERALDAS & $1153(1061-1289)$ & 1625 & $472(336-564)$ & 1.41 & 252 & 186 & 39 \\
\hline GALAPAGOS & $34(22-57)$ & 35 & $1(-22-13)$ & 1.02 & 106 & 0 & 0 \\
\hline GUAYAS & $\begin{array}{r}14882(14595- \\
15221)\end{array}$ & 31154 & $\begin{array}{r}16272 \text { (15933- } \\
16559)\end{array}$ & 2.09 & 710 & 1689 & 10 \\
\hline IMBABURA & $1414(1314-1455)$ & 1930 & $516(475-616)$ & 1.36 & 405 & 118 & 23 \\
\hline LOJA & $1688(1568-1788)$ & 2093 & $405(305-525)$ & 1.24 & 402 & 198 & 49 \\
\hline LOS RIOS & $2548(2403-2717)$ & 3842 & $\begin{array}{r}1294 \text { (1125- } \\
1439)\end{array}$ & 1.51 & 417 & 344 & 27 \\
\hline MANABI & $4660(4445-4863)$ & 7671 & $\begin{array}{r}3011(2808- \\
3226)\end{array}$ & 1.65 & 491 & 877 & 29 \\
\hline $\begin{array}{l}\text { MORONA } \\
\text { SANTIAGO }\end{array}$ & 347 (305-397) & 453 & $106(56-148)$ & 1.30 & 230 & 15 & 14 \\
\hline NAPO & $262(221-291)$ & 406 & $144(115-185)$ & 1.55 & 304 & 75 & 52 \\
\hline ORELLANA & $284(248-313)$ & 409 & $125(96-161)$ & 1.44 & 254 & 42 & 34 \\
\hline PASTAZA & $217(167-251)$ & 310 & $93(59-143)$ & 1.43 & 271 & 52 & 56 \\
\hline PICHINCHA & 9137 (8919-9460) & 14614 & $\begin{array}{r}5477 \text { (5154- } \\
5695)\end{array}$ & 1.60 & 453 & 1402 & 26 \\
\hline SANTA ELENA & $934(832-1006)$ & 2398 & $\begin{array}{r}1464(1392- \\
1566)\end{array}$ & 2.57 & 598 & 365 & 25 \\
\hline $\begin{array}{r}\text { SANTO } \\
\text { DOMINGO DE }\end{array}$ & & & & & & & \\
\hline $\begin{array}{r}\text { DOMINGO DE } \\
\text { LOS } \\
\text { TSACHILAS }\end{array}$ & $1457(1359-1555)$ & 2419 & 962 (864-1060) & 1.66 & 527 & 407 & 42 \\
\hline SUCUMBIOS & $430(365-487)$ & 684 & 254 (197-319) & 1.59 & 297 & 88 & 35 \\
\hline $\begin{array}{r}\text { TUNGURAHU } \\
A\end{array}$ & $1973(1878-2107)$ & 3117 & $\begin{array}{r}1144 \text { (1010- } \\
1239)\end{array}$ & 1.58 & 528 & 248 & 22 \\
\hline $\begin{array}{r}\text { ZAMORA } \\
\text { CHINCHIPE }\end{array}$ & $176(159-218)$ & 273 & $97(55-114)$ & 1.55 & 227 & 40 & 41 \\
\hline
\end{tabular}

*EDF: excess death factor. It is defined as the ratio between the number of observed deaths over the number of predicted deaths without COVID-19. 
medRxiv preprint doi: https://doi.org/10.1101/2021.02.25.21252481; this version posted March 1, 2021. The copyright holder for this preprint (which was not certified by peer review) is the author/funder, who has granted medRxiv a license to display the preprint in perpetuity.

It is made available under a CC-BY-NC-ND 4.0 International license .

The second wave occurred in July and early August, a period after strict lockdowns were gradually phased out. The number of weekly per capita deaths ranges between 5 and 8 per $10^{5}$ population or total weekly deaths between 2,200 and 2,500 (Fig. 1 and S2). These numbers are between 170\% and $190 \%$ of the expected number of deaths.

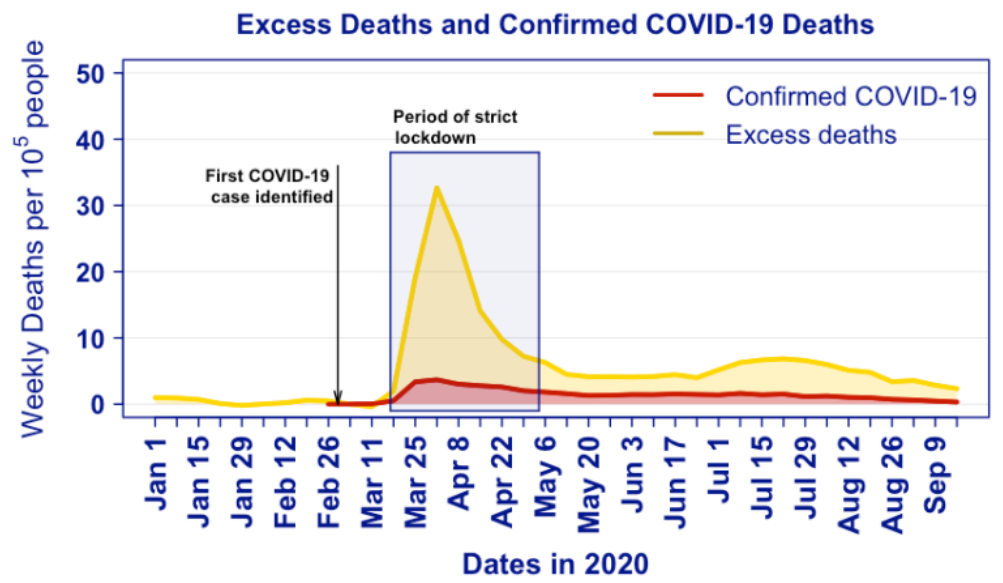

Figure 1. Time series for excess deaths (yellow) and documented COVID-19 deaths (red) per 100,000 people in Ecuador. The period of strict national lockdown by the Ecuador government (shaded area) is taken from the Oxford COVID-19 Government Response Tracker ${ }^{16}$.

\section{Excess deaths by sex and age and ethnicity}

We estimate that over the entire observational period, excess deaths were higher in men than women, i.e. 271 and 147 excess deaths per $10^{5}$ people for men and women, respectively (Fig. 2A). The observed death in men was $183 \%$ of expected levels, compared to $156 \%$ for women (Fig. S3A). Deaths was significantly elevated for all age groups greater than 40 years, with the number exponentially increasing with age group (Fig. 2B). For example, the number of excess deaths is 93 per $10^{5}$ people for the age group between 40 and 49 , and increases to 4,428 per $10^{5}$ people for the age group older than 80 . Across all age groups greater than 40 years old, more men died than women (Fig. 2C).
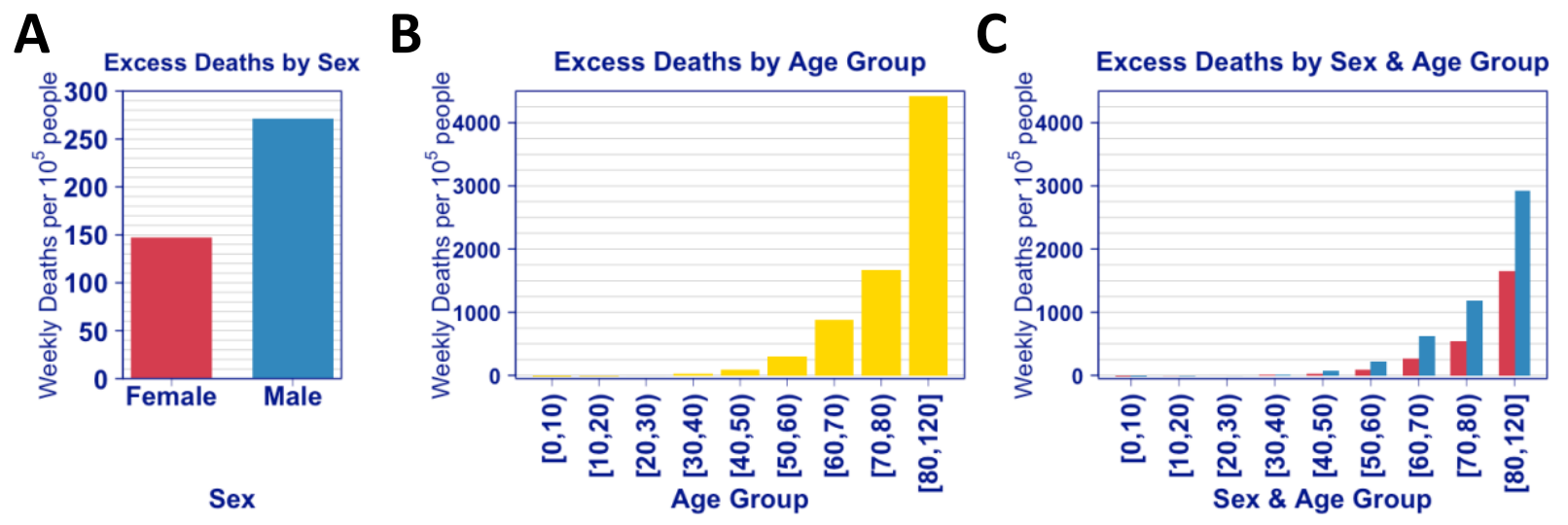

Figure 2. Excess deaths per 100,000 people by sex (A), by age group (B) and by sex and age group (C) in Ecuador. The numbers of excess deaths are normalized by the population size in each group. 
medRxiv preprint doi: https://doi.org/10.1101/2021.02.25.21252481; this version posted March 1, 2021. The copyright holder for this preprint (which was not certified by peer review) is the author/funder, who has granted medRxiv a license to display the preprint in perpetuity. It is made available under a CC-BY-NC-ND 4.0 International license .

Interestingly, we found that the numbers of deaths were $27 \%$ and $22 \%$ lower than expected for age groups between 0 and 9 years and between 10 and 19 years (Fig. S3B). A slight decrease of mortality in children has been observed in England ${ }^{17}$. One possible explanation is that the social distancing and restrictions during the pandemic may be protective for children from accidental deaths.

The sex and age characteristics in excess deaths are in line with the demographic characteristics of the risk of COVID-19 mortality ${ }^{18}$. The fact that the number of reported COVID-19 deaths only account for $20 \%$ of the total all-cause deaths suggests that a large fraction of COVID-19 deaths are undocumented, as a result of lack of COVID-19 testing ${ }^{4}$. To corroborate this hypothesis, we obtained COVID-19 testing and diagnoses data from the Ministry of Public Health (Methods), and calculated the weekly testing positivity rate, i.e. the number of COVID-19 cases over the total number of tests administered. The overall testing positivity rates in Ecuador using data up to September 23 is exceptionally high, i.e. $35 \%$. In particular, during the period between March $18^{\text {th }}$ and April $8^{\text {th }}$ when highest excess deaths and COVID-19 deaths are observed, the test-positivity rates are as high as $37-47 \%$ (Fig. S4). These rates are in stark contrast to the test positivity rate reported in other countries ${ }^{13}$. For example, in the US and the United Kingdom, where testing has been limited during the early period of COVID-19 outbreak, the test-positivity rates were between $20-30 \%$ in April, 2020 and dropped rapidly to below $10 \%$ since early May ${ }^{13}$. Therefore, the exceptionally high test-positivity rates in Ecuador are consistent with the hypothesis that the majority of excess deaths in Ecuador were caused directly by COVID-19 infection, but were not documented as COVID-19 deaths as a result of limited testing capacity.

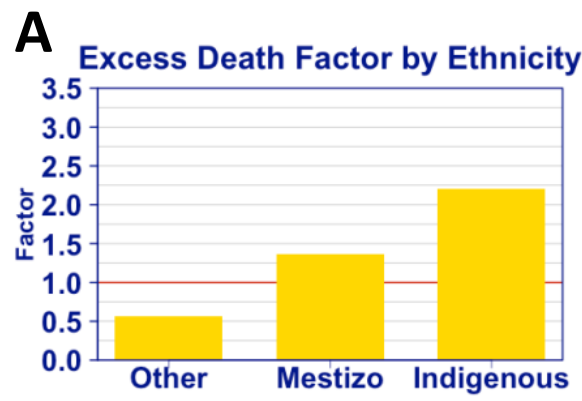

Ethnicity

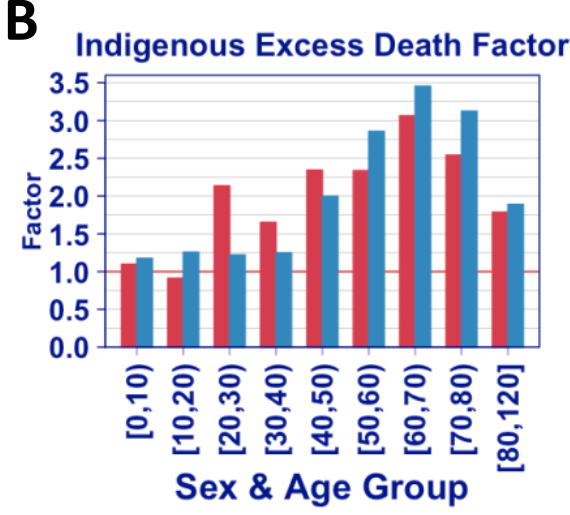

Figure 3. The excess death factor, i.e. the number of all-cause deaths over the number of expected deaths, by ethnicity (A) and by sex and age for the indigenous group (B).

We next analysed the excess deaths by ethnic groups in Ecuador, and found that the excess death factor for the indigenous group is 2.2 , i.e. excess deaths are $220 \%$ of the expected deaths compared to just $36 \%$ for the predominant ethnic group in Ecuador, i.e. mestizo group (Fig. 3A). The distribution of excess deaths by sex and age-group for the indigenous population is similar to the ones from the general population, except that excess death factors for females in the age-groups [20-30), [30-40), and [40-50), are larger than those from the corresponding male populations by $75 \%, 32 \%$ and $17 \%$ respectively (Fig. 3B). Ethnicity for death registrations is self-reported with typically $5 \%$ not being reported, but $25 \%$ not reported in 2020 . Even if all unreported ethnic data 
medRxiv preprint doi: https://doi.org/10.1101/2021.02.25.21252481; this version posted March 1, 2021. The copyright holder for this preprint (which was not certified by peer review) is the author/funder, who has granted medRxiv a license to display the preprint in perpetuity.

It is made available under a CC-BY-NC-ND 4.0 International license .

was not indigenous, our results would show that the indigenous group is much more disproportionally affected by COVID-19 than the confirmed death counts suggest.

\section{Spatial and temporal pattern of excess deaths at the provincial level}

Next, we examined the excess deaths at the provincial level. The highest total excess deaths occurred in Guayas and Pichincha, comprising of $29 \%$ and $18 \%$ of the excess deaths in Ecuador, respectively (Table 1). Note that the two provinces also reported the highest numbers of COVID19 deaths (Table 1). When the number of deaths is normalized by the population size in each province, Guayas and Santa Elena had the highest per capita deaths, at 710 and 598 per $10^{5}$ people, respectively (Table 1). Remarkably, the estimated excess death factors, i.e. the number of observed deaths over the number of expected deaths for Guayas, Pichincha and Santa Elena are 2.09, 1.60 and 2.57, respectively (Table 1). These exceptionally high levels of excess deaths rate emphasize the enormous burden of COVID-19 spread on mortality.

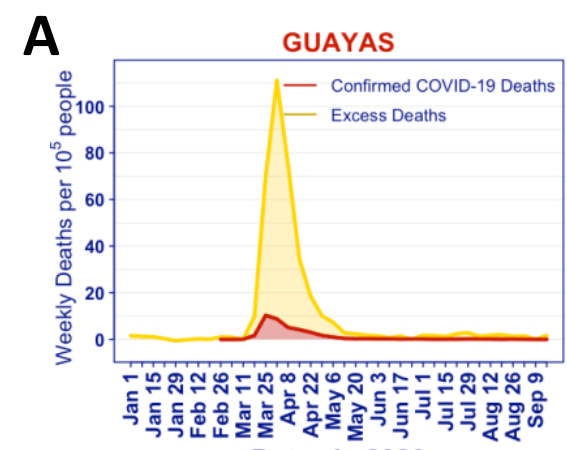

Dates in 2020

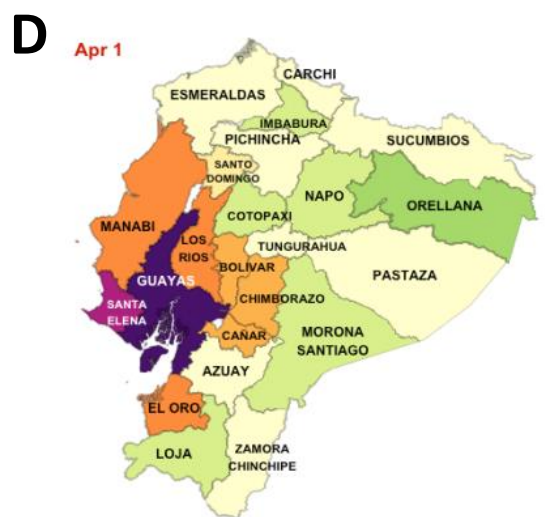

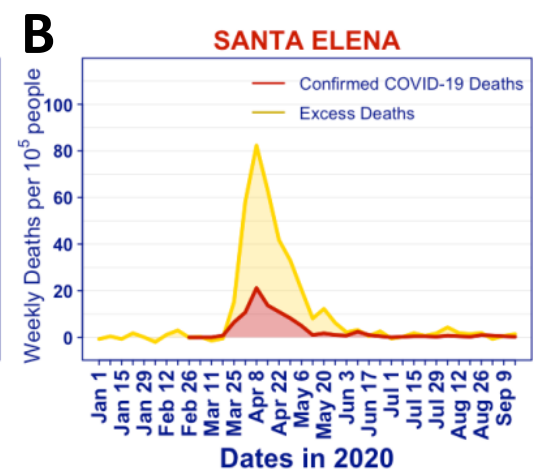

Dates in 2020

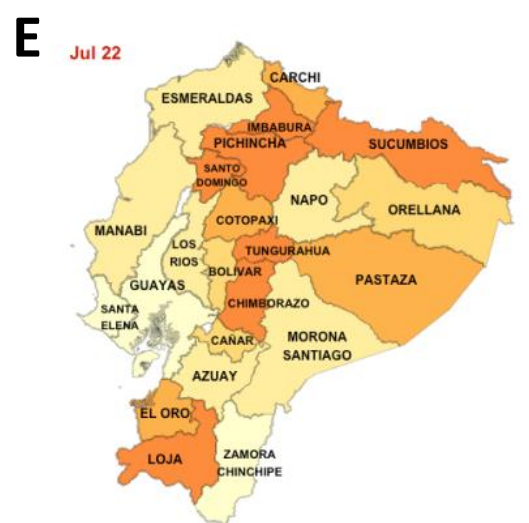

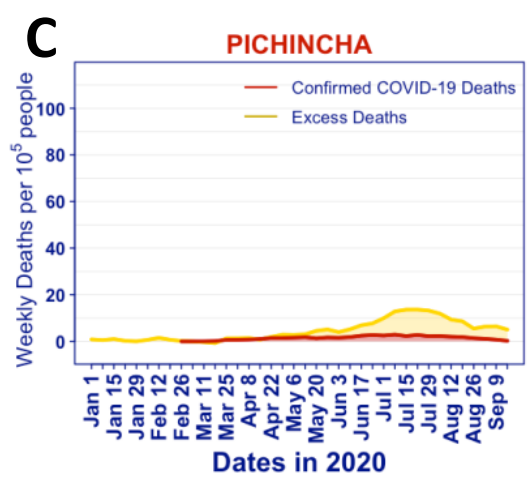

Dates in 2020

Figure 4. The spatial and temporal patterns of excess deaths in 2020 in Ecuador. (A-C) Time series for excess deaths (yellow) and documented COVID-19 deaths (red) per 100,000 people in Guayas, Santa Elena and Pichincha. (D and E) Provincial maps of Ecuador showing the number of excess deaths per $10^{5}$ population (colour) during the weeks of Apr 1-7 (panel D), and July 22-28, 2020 (panel E).

There is a strong spatial and temporal pattern in the magnitude and timing of excess deaths that are mostly consistent with the COVID-19 spread (as measured by COVID-19 deaths). In Guayas and Santa Elena, most excess death occurred during late-March and mid-May, 2020, with the highest numbers of weekly all-cause deaths and documented COVID-19 deaths occurred during the two weeks between April $1^{\text {st }}$ and $14^{\text {th }}$ (Fig. 4), leading to the first wave of all-cause deaths in Ecuador as seen in Fig. 1. During this period, the test-positivity rates in these provinces are 
medRxiv preprint doi: https://doi.org/10.1101/2021.02.25.21252481; this version posted March 1, 2021. The copyright holder for this preprint (which was not certified by peer review) is the author/funder, who has granted medRxiv a license to display the preprint in perpetuity. It is made available under a CC-BY-NC-ND 4.0 International license .

extremely high (between 40-80\%; see Fig. S4). Again, this highlights the burden of COVID-19 spread on the limited testing and health care capacity in Ecuador, and the notion that it is likely that a large fraction of COVID-19 deaths was not diagnosed or documented. The high burden of mortality is also apparent in provinces neighbouring Guayas and Santa Elena, such as Los Rios, Manabí, Bolivar, Chimborazo, Cañar and El Oro (Fig. 4D, S5 and S6).

In July and August, Pichincha, where the capital city, Quito, is located, became the COVID-19 epicentre during the second wave of excess deaths (Fig. 4C and 4E). Several other provinces close to Pichincha also have seen excess deaths peaked during this period. Again, the geographical and temporal trend in the excess deaths follows the spatial and temporal spread of COVID-19, as indicated by reported COVID-19 deaths (Fig. S5 and S6). For example, the provinces that had highest total deaths also had the highest number of reported COVID-19 deaths.

\section{Discussion}

We observed a very high level of total all-cause deaths, 87,762 in total or 502 per $10^{5}$ people between January 1, 2020 and September 23, 2020 in Ecuador. Analysing death records during 2015 and 2020, we estimated the number of excess deaths to be 36,402 or 208 per $10^{5}$ population. This is $171 \%$ of the expected number of deaths in a typical year and $71 \%$ of excess deaths. Comparing these numbers to estimates for other countries that have been heavily affected by COVID-19, such as the US, England and Wales and Brazil, we found that the level of excess deaths in Ecuador is approximately 2.9 and 2.3 folds of the estimate in the US and in England and Wales, respectively ${ }^{5,9}$, highlighting the enormous burden of COVID-19 on mortality in Ecuador.

The high level of excess deaths in Ecuador was reported previously in an online database ${ }^{13}$, newspapers ${ }^{14}$ and a research study ${ }^{15}$. These works were based on published numbers of all-cause deaths in Ecuador. Here, we provide analyses of a comprehensive set of individual death records between 2015 and 2020 with both geographical, temporal and demographic information. By fully accounting for spatial, temporal, geographical and demographic variations in the deaths in Ecuador over 6 years, our statistical model accurately estimates how the burden of excess deaths varies across time, geographical areas and demographic groups as we discuss below.

A distinguishing feature of excess deaths in Ecuador as compared to other countries, such as the US and England and Wales ${ }^{5,8,9}$ is that COVID-19 deaths $(7,410$ in total up to September 23, 2020) only account for a small fraction, i.e. $20 \%$, of all-cause excess deaths. Excess deaths can be caused directly by COVID-19 infection or indirectly as a result of COVID-19 related disruptions in society ${ }^{2,3}$. We do not have data on the causes of deaths in 2020, and thus are unable to assess the major cause of the large number of excess deaths not attributable to COVID-19 deaths. However, results of our analyses as listed below strongly suggest that the true number of COVID-19 deaths is underreported and a majority of excess deaths are likely to be caused directly by COVID-19, as seen in other countries ${ }^{8-11,12}$. First, the spatial and temporal patterns of excess deaths follow closely the spatial and temporal patterns of COVID-19 outbreaks in Ecuador as suggested by the COVID19 deaths counts. For example, high excess deaths occurred during periods when the number of COVID-19 deaths peaked in provinces most affected by COVID-19, such as Guayas, Santa Elena and Pichincha. Second, more men died than women, and the excess deaths become apparent for age groups greater than 40 years old and the number of excess deaths increases dramatically as 
medRxiv preprint doi: https://doi.org/10.1101/2021.02.25.21252481; this version posted March 1, 2021. The copyright holder for this preprint (which was not certified by peer review) is the author/funder, who has granted medRxiv a license to display the preprint in perpetuity. It is made available under a CC-BY-NC-ND 4.0 International license .

age increases. These demographic characteristics of mortality are consistent with the risk of COVID-19 mortality ${ }^{18}$ and are very similar to the demographics in excess deaths found in countries, such as England and Wales ${ }^{9}$ and Italy ${ }^{11}$, where the majority of excess deaths were attributable to COVID-19 deaths. Third, we found that the test-positivity rate in Ecuador, is extremely high over the period of COVID-19 outbreak, indicating the very low testing capacity in Ecuador $^{4}$. Therefore, it is likely that a lot of COVID-19 infections as well as deaths are not detected or documented. Indeed, anecdote evidence that people dying of pneumonia before being able to make to hospitals was reported during the early COVID-19 outbreak in Ecuador ${ }^{14}$. Overall, irrespective of the cause of the excess deaths, our analysis demonstrates the enormous burden of COVID-19 on mortality in Ecuador that is not revealed by the numbers of COVID-19 cases and deaths previously.

Non-pharmaceutical interventions played important roles in suppressing SARS-CoV-2 transmission and preventing deaths ${ }^{19}$. We found that in two provinces that had the most per capita excess deaths, i.e. Guayas and Santa Elena, the numbers of excess deaths decreased rapidly after the highest excess deaths occurred in the week of April 1-8. This rapid decline coincides with the strict social distancing measures implemented during March 17 and May 4, 2020 by the Ecuador government. These measures include a national lockdown, boarder closure, suspension of travel and strict confinement of citizens with a curfew ${ }^{16}$. Therefore, it is likely that the nonpharmaceutical interventions lead to reduced COVID-19 transmission and effectively averted the extremely rapid increases in deaths, as shown for COVID-19 outbreaks in other countries ${ }^{19}$. Note that the total all-cause deaths in Guayas and Santa Elena are extremely high, at 710 and 598 per $10^{5}$ population, corresponding to $209 \%$ and $257 \%$ of the numbers of expected deaths, respectively. Given the exponential growth nature of the outbreak in the absence of intervention efforts ${ }^{20-22}$, we reason that COVID-19 may have caused even more mortality than the observed high level if strict social distancing measures had been delayed or not been implemented at all. Thus, our results strongly suggest the importance of social distancing efforts in preventing deaths, and the potential devastating consequence in mortality if the strict non-pharmaceutical interventions especially during early COVID-19 outbreak were not implemented.

\section{Ethics approval}

Ethics committee approval was obtained from the Ecuadorian Ministry of Public Health. The analysis by Los Alamos National Laboratory team was approved by that institution's IRB.

\section{Funding}

The work is partially funded by the Laboratory Directed Research and Development (LDRD) Rapid Response Program through the Center for Nonlinear Studies at Los Alamos National Laboratory, and LDRD grants 20200699ER and 20210709ER. RK and SP would like to acknowledge funding from DARPA (HR0011938513), the Center for Nonlinear Studies. ERS was funded though NIH grant (R01AI135946). LC and NH would also like to acknowledge the US Department of Energy Office of Science through the National Virtual Biotechnology Laboratory, a consortium of national laboratories (Argonne, Los Alamos, Oak Ridge, and Sandia) focused on responding to COVID-19, with funding provided by the Coronavirus CARES Act. The funding source had no role in the design of the study, execution, analyses, interpretation of the data, or decision to publish. 
medRxiv preprint doi: https://doi.org/10.1101/2021.02.25.21252481; this version posted March 1, 2021. The copyright holder for this preprint (which was not certified by peer review) is the author/funder, who has granted medRxiv a license to display the preprint in perpetuity.

It is made available under a CC-BY-NC-ND 4.0 International license .

\section{Data Availability Statement}

The data underlying this article cannot be shared publicly due to Ecuador government regulations that the Ecuadorian Ministry of Public Health must approve the research protocol to release reusable COVID-19 datasets. The data may be shared on reasonable request to the corresponding authors and the Ecuadorian Civil Registry.

\section{Author contributions}

Conceptualisation: LC, IT, ERS, NH and RK; data acquisition: IT; methodology and formal analysis: LC, ERS, RM, NO, SP and NH; funding acquisition: LC and RK; underlying data validation: LC, IT and NH; visualisation and writing: LC and RK.

\section{Declaration of interests}

We declare no competing interests. 
medRxiv preprint doi: https://doi.org/10.1101/2021.02.25.21252481; this version posted March 1, 2021. The copyright holder for this preprint (which was not certified by peer review) is the author/funder, who has granted medRxiv a license to display the preprint in perpetuity. It is made available under a CC-BY-NC-ND 4.0 International license .

\section{References:}

1. WHO. WHO Coronavirus Disease (COVID-19) Dashboard. 2020 [cited Jan 13, 2021]; Available from: https://covid19.who.int

2. Kiang MV, Irizarry RA, Buckee CO, Balsari S. Every Body Counts: Measuring Mortality From the COVID-19 Pandemic. Ann Intern Med 2020; 173: 1004-7.

3. Leon DA, Shkolnikov VM, Smeeth L, Magnus P, Pechholdova M, Jarvis CI. COVID-19: a need for real-time monitoring of weekly excess deaths. Lancet 2020; 395: e81.

4. Torres I, Sacoto F. Localising an asset-based COVID-19 response in Ecuador. Lancet 2020; 395: 1339.

5. Woolf SH, Chapman DA, Sabo RT, Weinberger DM, Hill L, Taylor DDH. Excess Deaths From COVID-19 and Other Causes, March-July 2020. JAMA 2020; 324: 1562-4.

6. Weinberger DM, Chen J, Cohen T, et al. Estimation of Excess Deaths Associated With the COVID-19 Pandemic in the United States, March to May 2020. JAMA Intern Med 2020; 180: 1336-44.

7. Bilinski A, Emanuel EJ. COVID-19 and Excess All-Cause Mortality in the US and 18 Comparison Countries. JAMA 2020; 324: 2100-2.

8. Rossen LM, Branum AM, Ahmad FB, Sutton P, Anderson RN. Excess Deaths Associated with COVID-19, by Age and Race and Ethnicity - United States, January 26-October 3, 2020. MMWR Morb Mortal Wkly Rep 2020; 69: 1522-7.

9. Aburto JM, Kashyap R, Scholey J, et al. Estimating the burden of COVID-19 on mortality, life expectancy and lifespan inequality in England and Wales: A population-level study. medRxiv 2020: 2020.07.16.20155077.

10. Michelozzi P, de'Donato F, Scortichini M, et al. Temporal dynamics in total excess mortality and COVID-19 deaths in Italian cities. BMC Public Health 2020; 20: 1238.

11. Scortichini M, Schneider Dos Santos R, De' Donato F, et al. Excess mortality during the COVID-19 outbreak in Italy: a two-stage interrupted time-series analysis. Int J Epidemiol 2021; 49: 1909-17.

12. Carvalho TA, Boschiero MN, Marson FAL. COVID-19 in Brazil: 150,000 deaths and the Brazilian underreporting. Diagn Microbiol Infect Dis 2020; 99: 115258.

13. ourworldindata.org. Coronavirus Pandemic (COVID-19). 2020 [cited January 13, 2020]; Available from: https://ourworldindata.org/coronavirus

14. Cabrera JML, Kurmanaev A. Ecuador's Death Toll During Outbreak Is Among the Worst in the World. The New York Times. 2020.

15. Cevallos-Valdiviezo H, Vergara-Montesdeoca A, Zambrano-Zambrano G. Measuring the impact of the COVID-19 outbreak in Ecuador using preliminary estimates of excess mortality, March 17-October 22, 2020. Int J Infect Dis 2020.

16. Hale, Thomas, Webster S, Petherick A, Phillips T, Kira B. Oxford COVID-19 Government Response Tracker, Blavatnik School of Government. . Data use policy: Creative Commons Attribution CC BY standard 2020.

17. Ladhani SN, Amin-Chowdhury Z, Davies HG, et al. COVID-19 in children: analysis of the first pandemic peak in England. Arch Dis Child 2020; 105: 1180-5.

18. Verity R, Okell LC, Dorigatti I, et al. Estimates of the severity of coronavirus disease 2019: a model-based analysis. Lancet Infect Dis 2020; 20: 669-77.

19. Flaxman S, Mishra S, Gandy A, et al. Estimating the effects of non-pharmaceutical interventions on COVID-19 in Europe. Nature 2020; 584: 257-61. 
medRxiv preprint doi: https://doi.org/10.1101/2021.02.25.21252481; this version posted March 1, 2021. The copyright holder for this preprint (which was not certified by peer review) is the author/funder, who has granted medRxiv a license to display the preprint in perpetuity. It is made available under a CC-BY-NC-ND 4.0 International license.

20. Ke R, Romero-Severson EO, Sanche S, Hengartner N. Estimating the reproductive number R0 of SARS-CoV-2 in the United States and eight European countries and implications for vaccination. medRxiv 2020: 2020.07.31.20166298.

21. Romero-Severson EO, Hengartner N, Meadors G, Ke R. Change in global transmission rates of COVID-19 through May 6 2020. PLoS One 2020; 15: e0236776.

22. Sanche S, Lin YT, Xu C, Romero-Severson E, Hengartner N, Ke R. High Contagiousness and Rapid Spread of Severe Acute Respiratory Syndrome Coronavirus 2. Emerg Infect Dis 2020; 26: $1470-7$. 